RFP-1965

December 19, 1973
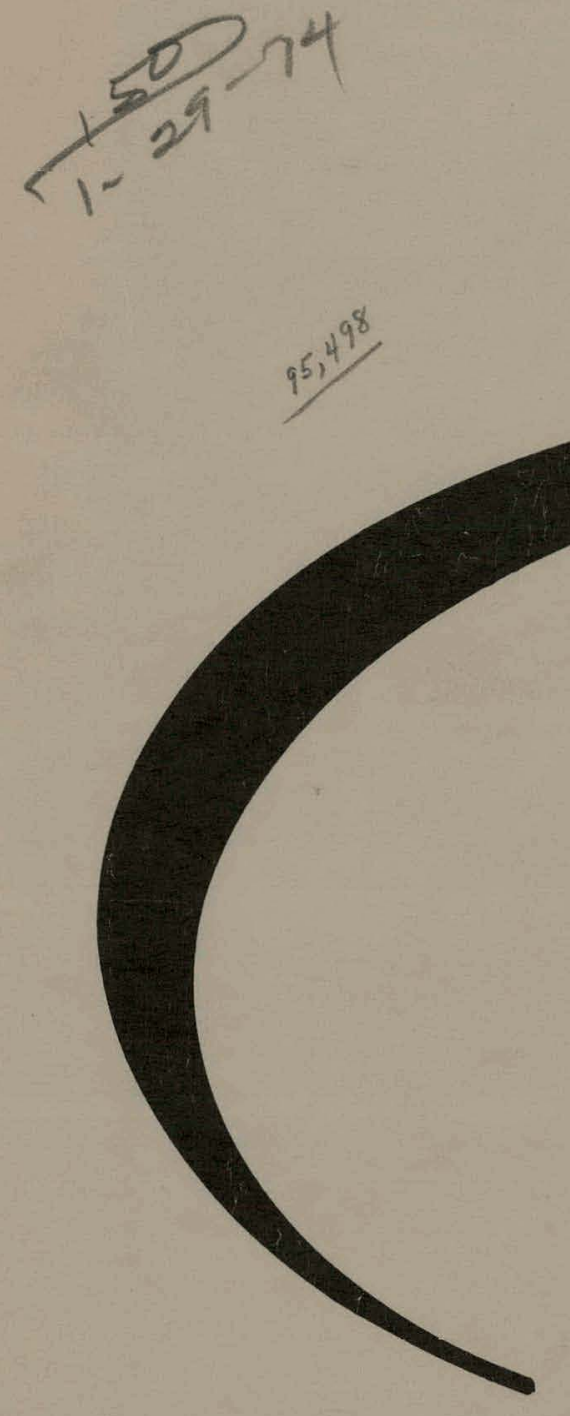

\title{
DESIGN DATA FOR HOLLOW CATHODE GAS-FED ARCS
}

Duane G. Williams

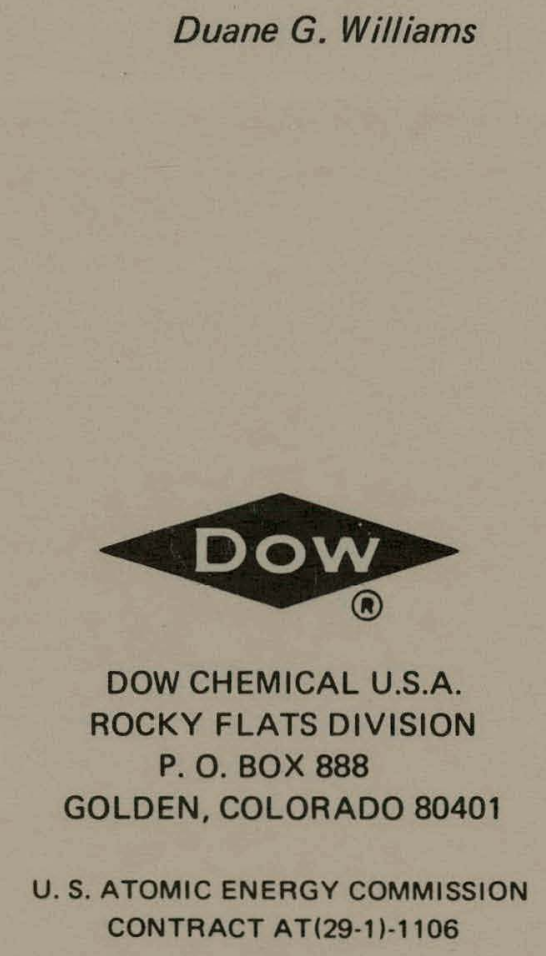




\section{DISCLAIMER}

This report was prepared as an account of work sponsored by an agency of the United States Government. Neither the United States Government nor any agency Thereof, nor any of their employees, makes any warranty, express or implied, or assumes any legal liability or responsibility for the accuracy, completeness, or usefulness of any information, apparatus, product, or process disclosed, or represents that its use would not infringe privately owned rights. Reference herein to any specific commercial product, process, or service by trade name, trademark, manufacturer, or otherwise does not necessarily constitute or imply its endorsement, recommendation, or favoring by the United States Government or any agency thereof. The views and opinions of authors expressed herein do not necessarily state or reflect those of the United States Government or any agency thereof. 


\section{DISCLAIMER}

Portions of this document may be illegible in electronic image products. Images are produced from the best available original document. 


\section{LEGAL NOTICE}

'This report was prepared as an account of work sponsored by the United States Government. Neither the United States nor the United States Atomic Energy Commission, nor any of their employees, nor any of their contractors, subcontractors, or their employees, makes any warranty, expressed or implied, or assumes any legal liability or responsibility for the accuracy, completeness or usefulness of any information, apparatus, product or process disclosed, or represents that its use would not infringe privately owned rights.

Printed in the United States of America

Available from the

National Terhniral Information Servire

U. S. Department of Commerce

Springfield, Virginia 22151

Price: Printed Copy $\$ 4.00$ Microfiche $\$ 1.45$ 
Printed

December 19, 1973
RFP-1965

UC-38 ENGINEERING

AND EQUIPMENT

TID-4500-R60

\section{DESIGN DATA FOR HOLLOW CATHODE GAS-FED ARCS}

Duane G. Williams

Research and Ecology

COATING GROUP

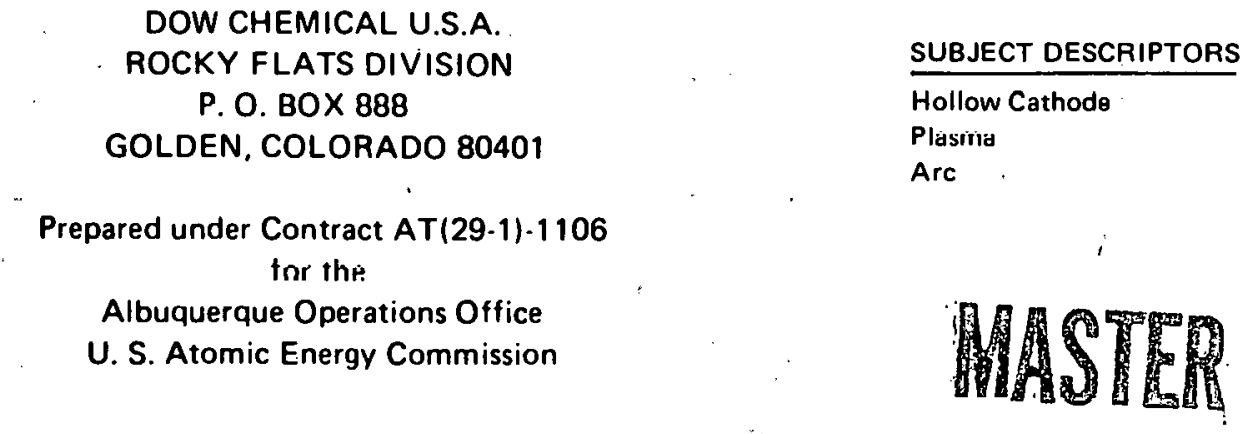


RFP-1965 
CONTENTS

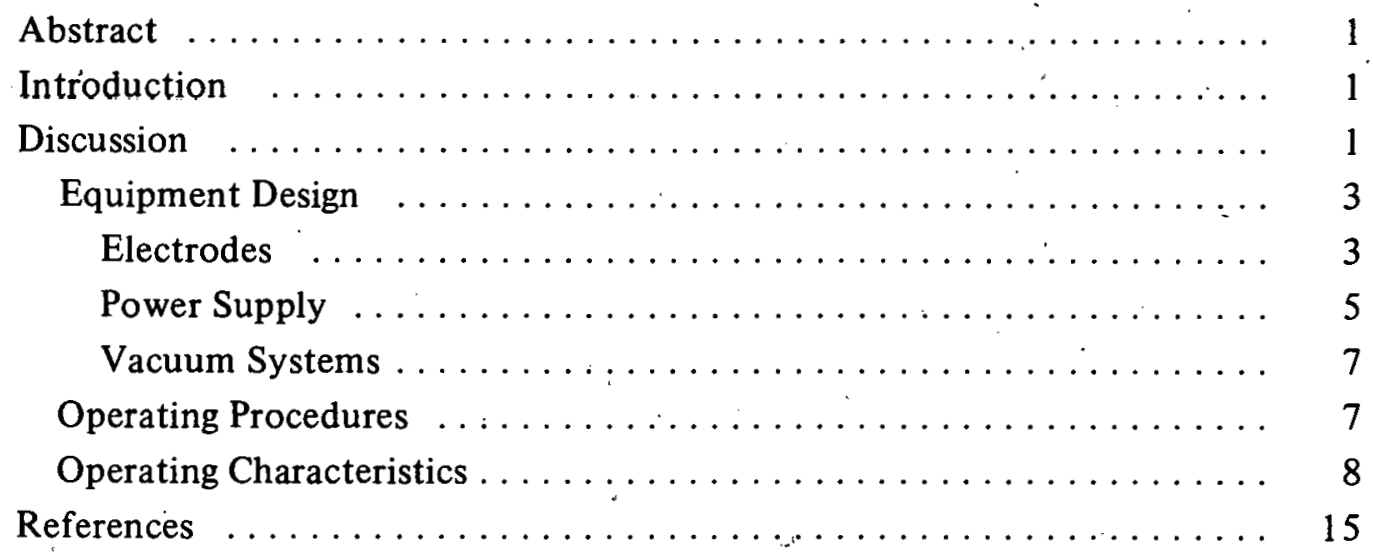


RFP-1965 


\title{
DESIGN DATA FOR HOLLOW CATHODE GAS-FED ARCS -
}

\author{
Duane G. Williams
}

\begin{abstract}
Engineering information has been provided to fabricate and operate equipment for generating hollow cathode arcs. Topics include equipment selection and design, operating procedures, and operating characteristics. Hollowcathode operating characteristics for a wide range of cathode sizes, gas-flow rates, gas types, and cathode-anode spacings are covered.
\end{abstract}

\section{INTRODUCTION}

The hollow cathode gas-fed arc serves as one of the best available sources for producing a high energy plasma beam. ${ }^{1}$ The equipment required to generate the arc consists of little more than a refractory metal tube (usually called a hot hollow cathode), a method of flowing small quantities of gas through the tube into a vacuum, and use of a power supply connected to the tube to maintain the arc. A typical arrangement of these components is shown in Figure 1. The resultant arc appears as a slender column of brilliant light extending from the cathode tube to the anode a few centimeters away. Longer arcs of almost any length are possible with magnetic confinement. The arcs are stable and typically carry currents of hundreds of amperes.

The early development of the hollow cathode gasfed arc was attributed to Luce (1) ${ }^{2}$ or Lidsky et al. (2). Since then arcs have been studied by many investigators.

Several articles ( 3 through 13) have been presented which describe the basic plasma parameters of such arcs. These studies, performed under widely varying conditions, show plasma densities of $10^{13}$ to $10^{14}$ centimeters $^{-3}(\mathrm{~cm})$, ion- and electrontemperatures as high as 30 electronvolts $(\mathrm{eV})$, and in some cases, nearly complete ionization. The high current arc can be used as a heating source

\footnotetext{
'NUTE': Yublication of the data has been delayed since April 1972 in order to clear patent review requirements.

${ }^{2}$ Numerals in parentheses relate to references at end of text.
}

because each electron arriving at the anode surrenders energy equal to the work function of the anode material plus its kinetic energy.

Calorimetric measurements in the laboratory at Rocky Flats have shown that about 80 percent of the electrical energy applied to the cathode tube dissipates as heat at the anode. Because of the high efficiency, the hollow cathode arc has been used as a heating source for various metallurgical processes (14 through .18).

The hollow cathode arc has also been used as an energy. source for argon-ion lasers (19 through 23). Coaxial, multichannel, and other variations of the single tube arc have been developed $(14,24,25,26)$.

At Rocky Flats, hollow cathode arcs have been investigated as a plasma source for the deposition of triode-sputtered coatings and as a source of heat to evaporate metal for use as metal coatings.

Despite the numerous articles published which describe various features of the hollow cathode arc, none provides the reader with sufficient engineering information to construct hollow cathode equipment. Presumably each of the researchers developed his own equipment using a tedious trial and error process. The purpose of this report is to provide the reader with sufficient information to design and operate hollow cathode equipment with a minimum of problems.

\section{DISCUSSION}

Information useful for the selection, hookup, and operation of hollow cathode equipment follows. Areas covered include equipment design, operating procedures, and operating characteristics.

The section on equipment design covers design of the cathode, cathode shield, and anode. Details are given also on the selection and interconnection 


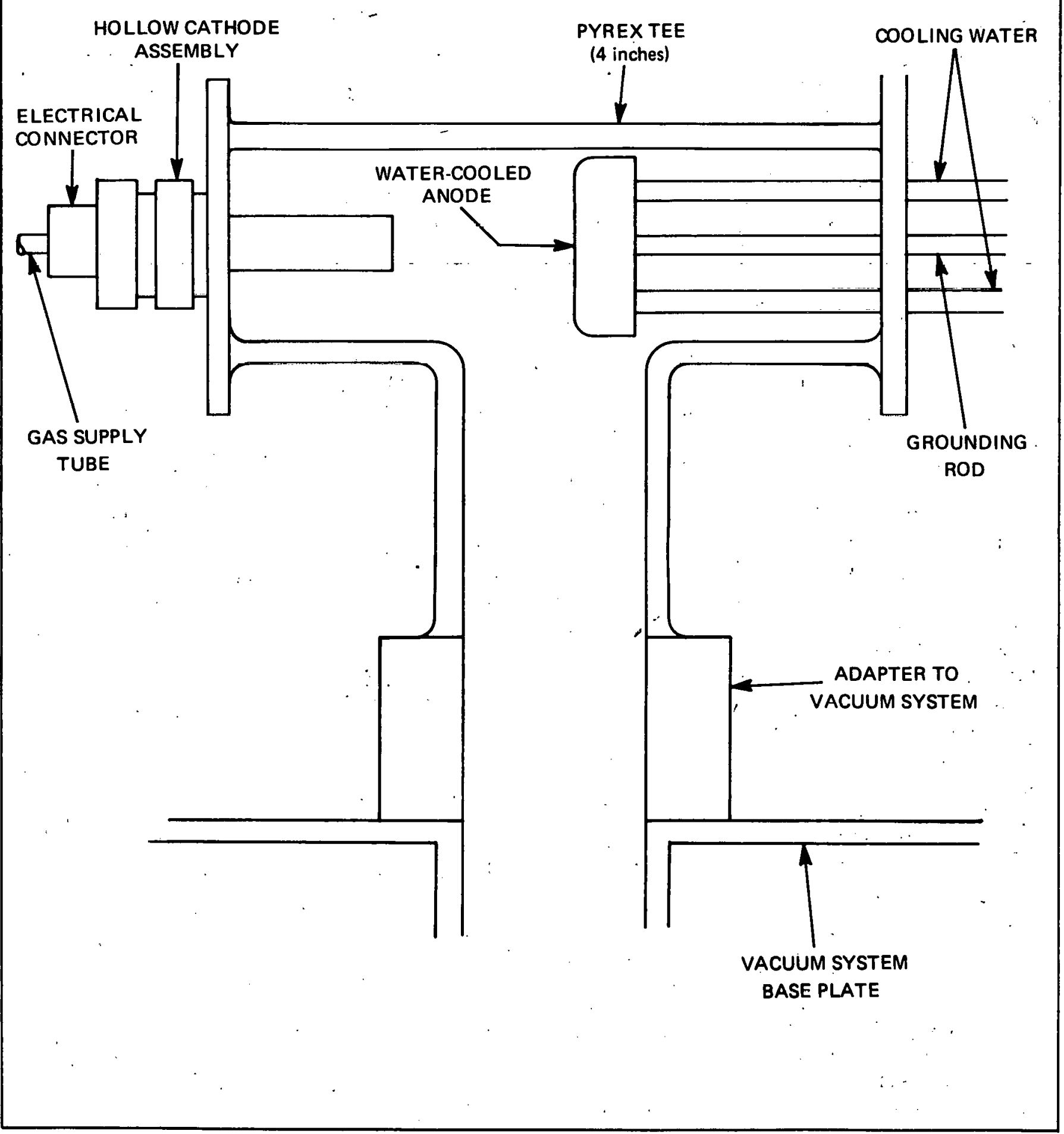

FIGURE 1. Apparatus for Producing Hollow Cathode Arcs. 
of power supplies. Vacuum system requirements are discussed.

The operating procedures outline a method for igniting hollow cathode arcs that minimizes the amount of cathodc material sputtered around the vacuum chamber and reduces the risk of uncontrolled arcing.

The operating characteristics relate to the effect of changing cathode dimensions, gas-flow rates, gas type, and cathode-anode spacing. Voltage-current curves for hollow cathode arcs operating under a wide range of conditions are presented. The efficiency of the arc as a heating source and the hollow cathode life are discussed. The data show the hollow cathode arc as a simple, reliable source for metallurgical heating in which about 80 percent of the electrical energy supplied to the cathode can be converted to useful heat.

\section{Equipment Design:}

A complete cathode assembly consists of a cathode tube, a cathode-support post, and a cathode shield. The design, considered the best of four used by the author, is shown in Figure 2. For sake of clarity, baffles which assure cooling water to circulate the full length of the cathode shield are not shown in the figure.

\section{ELECTRODES-}

Although the hollow cathode assembly is not complex, certain design criteria must be observed to insure proper operation. The most critical of these occur in the design of the cathode shield. If the cathode tube is not properly shielded, arcing will occur all over the outside of the tube instead of inside the tube, as desired. The arcing causes severe etching and sputtering of the cathode tube and cathode material deposits all over the inside of the vacuum chamber. Spacing between the shield and the tube should be as small as possible (no more than one-quarter centimeter). The shield should be electrically floating. If it is grounded, arcing tends to occur between it and the cathode tube, of ten with disastrous results. Cathode shields used to prevent arcing should be water-cooled because the cathode radiates considerable energy. The measurements herein indicate a 0.25 -inch $(0.64 \mathrm{~cm})$ outside diameter cathode tube typically radiates about a one-half kilowatt.

To attempt construction of a hollow cathode assembly which is entirely enclosed within an ordinary vacuum bell jar is not advisable. All portions of the cathode assembly which are at cathode potential, for example cooling water or gas-feed lines, are subject to arcing. Because of the large capacity of the power supplies used to energize the arc, damage to equipment will probably occur. A far better procedure is to design the hollow cathode assembly into the wall of the vacuum chamber. Thus most of the assembly at cathode potential remains outside the chamber, and only the cathode tube is inside. If the outside of the tube is properly shielded, arcing will occur only at the tip of the tube and ignition of the plasma will occur quickly. Under these conditions, little cathode material will be sputtered around the inside of the chamber.

Tungsten, tantalum, and dispenser-type cathodes have been used by other researchers, but only tantalum cathodes have been investigated by the author. These have advantages since machining can be done in a variety of sizes from solid tantalum rods. The type fabricated at the plant is shown in Figure 3. Recent work indicates that shorter cathodes with an overall length of 1.5 inches $(3.8 \mathrm{~cm})$ are equally good. One end of the cathode is threaded so it can be screwed into a stainless steel (Type-304) support post. A hole is drilled axially through the support post for gas feed. The post should also be cooled, although the rate of energy conduction into it usually amounts to less than 100 watts.

Steps should be taken to insure that the flat mating surface between the cathode and the cathode support post has been carefully machined.

If sizeable gas leaks start at this point, the resulting higher pressure will cause arcs to occur between the tube and shield, even if the shield is electrically floating. A small quantity of tungsten diselenide powder on the threads permits easy removal of the 


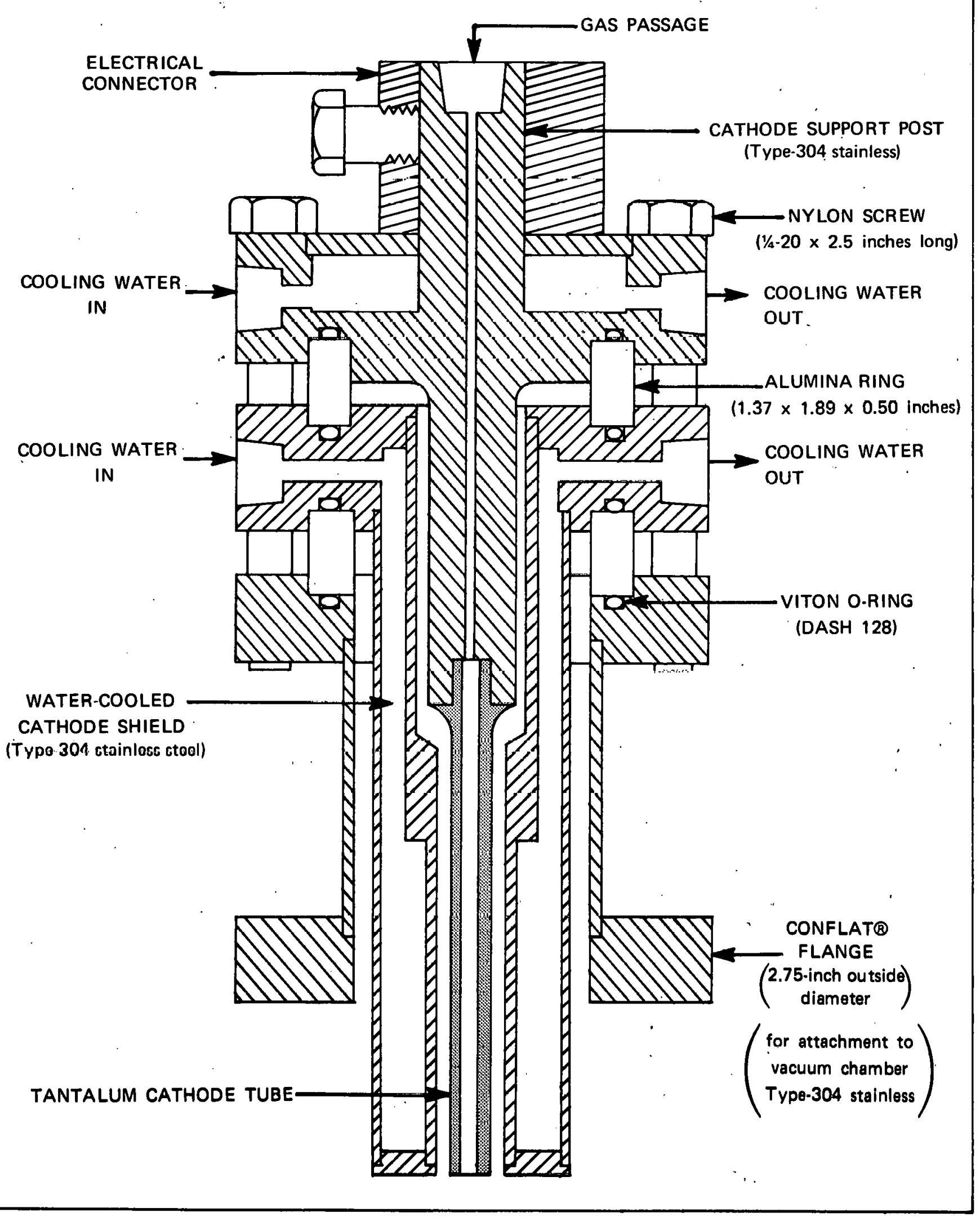

FIGURE 2. Cross Section of Hollow Cathode Assembly. 


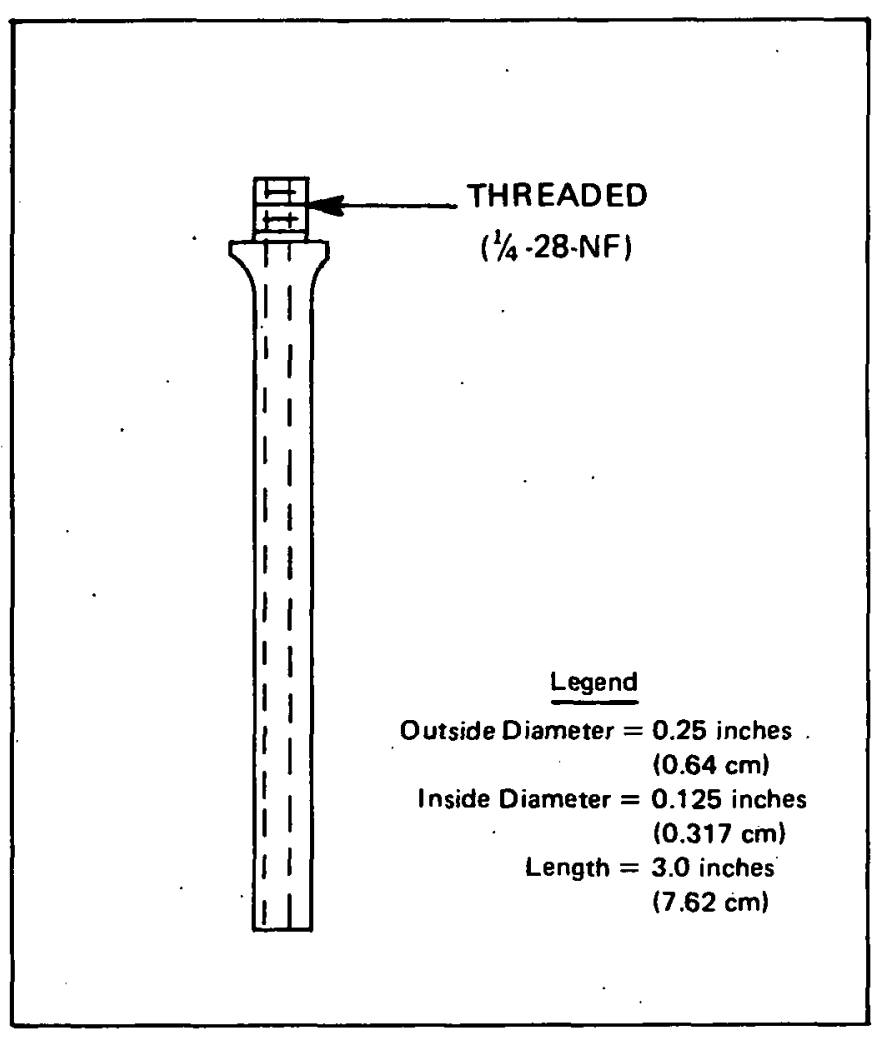

FIGURE 3. Tantalum Cathode Tube.

cathode tubes after use. Data for selecting other suitable cathode tube diameters are detailed in the last section (see Figure 8).

Design of the anode is not critical. A water-cooled copper block is adequate. Cooling is necessary, since most of the electrical energy supplied at the cathode eventually dissipates as heat at the anode.

\section{POWER SUPPLY-}

The selection of electrical power supplies presents some problems. For cathodes of the size described, a DC power supply rated at about 300 volts and 10 amperes is required to heat the cathode to the point where electron emission is sufficient to start the arc. Once the arc is established, ion bombardment heats the cathode, and the potential required to maintain the arc falls sharply while the current . rises. After this occurrence, a low-voltage, highcurrent DC power supply, capable of at least a hundred amperes, must be used to maintain the arc. Although possible to obtain a single power supply capable of 300 volts and hundreds of amperes, such supplies are bulky, not readily available, and expensive. Because the higher voltage and current capabilities of such a supply are not utilized simultaneously, more economical use can be achieved with two power supplies. A method for interconnecting the two power supplies is illustrated schematically in Figure 4.

The higher voltage starting power supply can readily be fabricated from a variable transformer, a stepup transformer, and a diode bridge. No regulation of filtering is required. A DC power supply rated at 300 volts and 10 amperes will be sufficient to start all the cathodes described herein, providing the length of the arc does not exceed $15 \mathrm{~cm}$. Larger diameter and thicker-walled cathodes or longer arcs will require a larger power supply. If a commercial power supply were used, the original diodes will probably have to be replaced with diodes having a higher rating. Voltage spikes emanating from the plasma, especially during startup, require diodes with voltage and current ratings at least three times the power supply rating being used. The IN376b diodes ( 800 peak inverse volts, 35 amperes) should be the minimum rated diodes considered.

During starting, the transition to the arc mode is sometimes abrupt and a current-limiting resistor (Figure 4) should be used on the output of the starting power supply. One or two 1000-watt, 115-volt heater cones in series work well. (Type415A Glocoils, manufactured by Eagle Electric Manufacturing Company, Long Island City, New York, are suitable.) The 1 kilovolt (kV), 1 microfarad ( $\mu \mathrm{f})$ Mylar capacitor also shown in Figure 4, helps to protect the diodes in the starting power supply.

A DC welder produces an ideal low voltage, high current power supply for maintaining the arc, providing the ultimate use of the plasma does not require precise voltage regulation. Besides being rugged, welders are usually equipped with high frequency starters which can be conveniently used to start the discharge in the cathode tube. A current-regulated welder should be used if the hollow cathode were operated under the conditions represented by the negative resistance (Figure 5) 


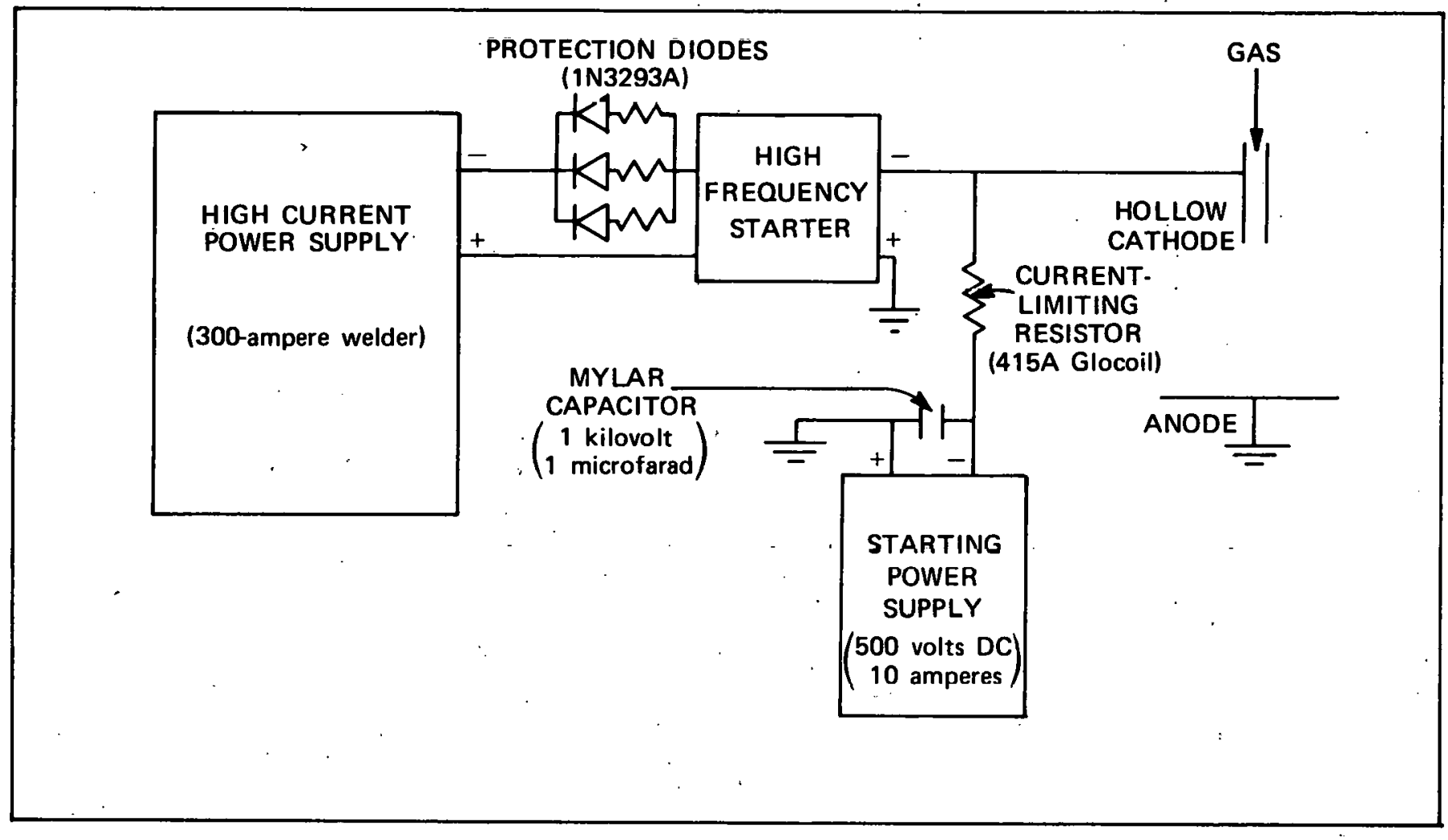

FIGURE 4. Schematic of Power Supply Interconnection.

FIGURE 5. Voltage-Current Curve for a Typical Gas Discharge.

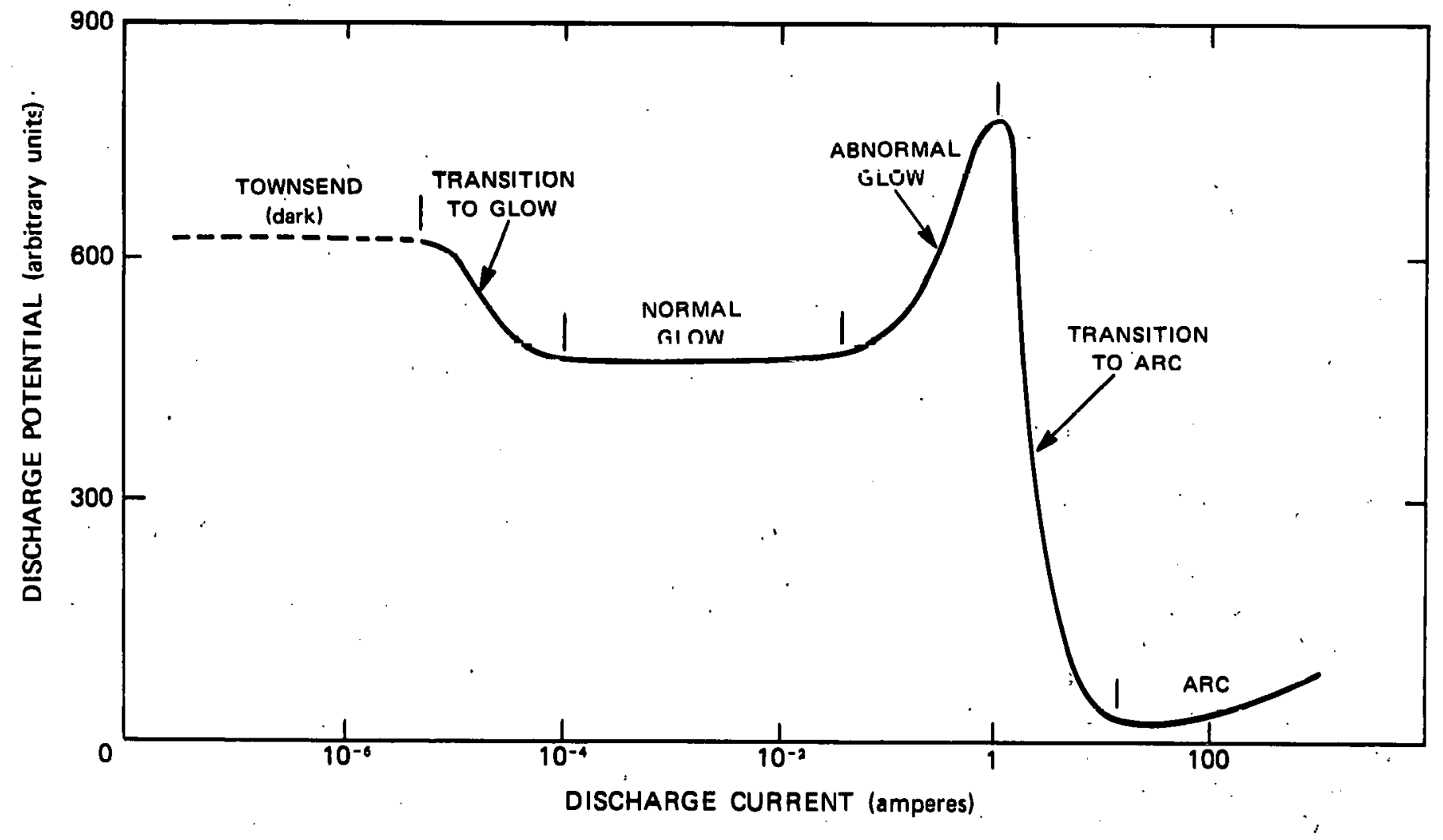


portion of the potential-current curves. A voltageregulated power supply may be used if an additional resistance is placed in series with the plasma beam. The resistance must be large enough to insure that the total resistance presented to the power supply is positive. Auxiliary diodes, also shown in Figure 4, are usually required to protect the diodes of the high current power supply, which normally would not be rated to withstand the higher starting voltages. The best place to locate these diodes is between the welder and the high frequency starter. This location is chosen because the starters are equipped with protective circuitry that prevents high voltage spikes generated by the starter from being fed back onto the low voltage rectifiers of the welder. This circuitry will also protect the auxiliary diodes from any high voltage transients occurring as a result of hollow cathode operation. Three parallel IN3293A diodes (600 peak inverse volts, 100A) were used by the author. A small resistance must be placed in series with each of the diodes to assure the current divides equally among them.

\section{VACUUM SYSTEMS-}

Vacuum systems used in conjunction with hot hollow cathodes must be of sufficient capacity to handle the gas supplied to the cathode in addition to the normal gas load. For cathodes of the sizes described, gas flows of 20 to 50 (atmosphere) cubic centimeters per minute are required to maintain the arc. If the chamber pressure away from the arc is kept below a few millitorr, the arc will be confined to a narrow beam. If the chamber pressure is higher, the discharge will fill the entire chamber. A good 4-inch $(10.2 \mathrm{~cm})$, diffusionpumped vacuum system with a liquid nitrogen trap will provide the minimum pumping rate necessary for the operation of hollow cathode arcs. A similar system was used to prepare all the data presented herein.

When starting the arc, the usual procedure is to raise the chamber pressure to about 20 millitorr. If the vacuum system is equipped with a manually operated main valve, the chamber pressure can be controlled by throttling with the valve. If the main valve is air-operated, throttling becomes impossible, and a small diameter bypass with a throttling valve should be installed around the main valve.

\section{Operating Procedures:}

The procedures outlined will be for the operation of hollow-cathode-arc equipment with two power supply connectors, as outlined in the preceding section.

After evacuation of the chamber, the low voltage, high current power supply (the welder) should be turned on and the current controls adjusted to a setting of 50 to 100 amperes. Because no discharge occurs at this point, no current should flow. Argon (or other gas) may now be admitted through the cathode at a flow rate of about 50 (atmospere) cubic centimeters per minute. This will vary somewhat with cathode size and anode-cathode distance. If the high current power supply is a welder equipped with a high frequency starter, the starter can be used to ignite the discharge. If no such. starter is available, a Tesla coil of the type sold by laboratory supply houses for the detection of leaks in glass vacuum systems may be used to start the discharge. In order to start the discharge, the chamber pressure must be at least 10 millitorr. Raising the pressure to this level or higher can be accomplished by throttling with the main valve, or otherwise partially restricting the flow of gas from the chamber to the vacuum pumps. With the application of the high frequency potential to the cathode, a feeble discharge will appear at the end of the tube. Unce this occurs, the chamber pressure should be reduced to the minimum pressure which will sustain the discharge. This precaution will minimize any undesirable arcing between the cathode tube and shield.

To convert the low current discharge to the arc mode, the temperature of the cathode must be raised until sufficient electron emission occurs to start the arc. This is done by gradually increasing the cathode potential with the starting power supply. The intensity of the discharge increases as the potential increases and the cathode is heated to a brilliant white. Visual observation requires eye protection. When electron emission is sufficient, the potential required to maintain the discharge falls 
sharply, and cathode current increases to the value previously set on the high current power supply. As soon as this occurs, the starting power supply should be turned off since its load approaches zero. The high frequency starter may also be turned off at this time. The gas flow may then be reduced to lower values which may be determined from the curves presented in Figure 6. The cathode current may also be adjusted to other values by using the high current power supply controls. The arc produced should be stable and capable of operation for long periods of time.

\section{Operating Characteristics:}

The macroscopic operating characteristics of the hollow cathode arc are only briefly covered in the literature. Cathode potential versus cathode current curves have been presented for only a few cases (14 through 18). and often these curves have been presented without sufficient supporting data to make them meaningful. Theoretical predictions of operating characteristics are difficult, because the theory of hollow cathode arcs, similar to the theory of all arcs, remains in a primitive state. The major obstacle to the theoretical approach is the lack of a satisfactory explanation for the extremely high-electron emission currents observed. The usual emission equations do not apply. Many theories to explain the high emission currents have been proposed, but they have not received wide acceptance. Hoyaux (27) has reviewed this subject in detail.

The voltage-current curves for hollow cathode discharges are similar to those for most $\mathrm{DC}$ discharges (see Figure 5). When the hollow cathode discharge is first ignited, using the procedures previously described, the discharge operates in the hollow cathode equivalent of the normal or abnormal glow discharge regions depending on the operating characteristics of the high current poiwer supply. Application of higher voltage by the starting power supply forces the discharge over the peak of the abnormal glow region into the transition to arc and arc regions. This change is abrupt, unstable,

FIGURE G. The Effect of Argon Flow Rate on Hollow Cathode Pperation.

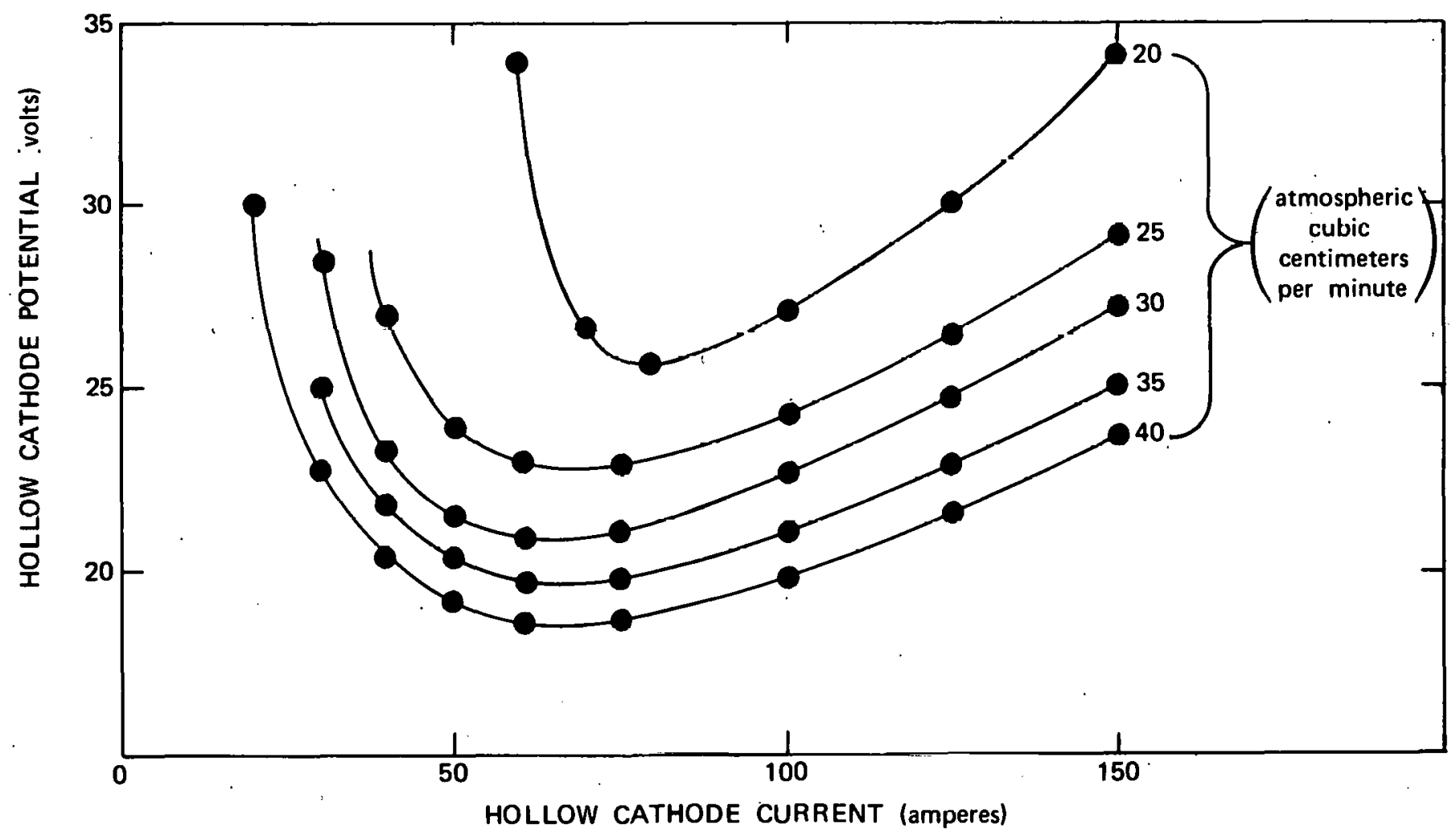


and difficult to reproduce. For this reason, the data presented here cover the lower portion of the transition to arc region and the arc region only.

A number of factors affect the operating characteristics of the hollow cathode arc. The most important of these, not necessarily in order, are:

1. The rate of gas flow through the cathode tube.

2. The type of gas used.

3. Inside and outside diameters of the cathode tube.

4. Cathode-to-anode spacing.

5. Cathode and anode materials.

6. The strength of external applied magnetic fields, if any.

The first four factors have been investigated by the author. The fifth and sixth have not. In these investigations, only tantalum cathode tubes and copper anodes have been used. No external magnetic fields were used in this work.

The apparatus used in these investigations was assembled as shown in Figure 1. The cathode tubes were those shown in Figure 2, except in those experiments where the cathode diameters were varied. The anode used was a $3.94-\mathrm{inch}(10.0-\mathrm{cm})$ diameter, water-cooled copper block with a flat surface facing the cathode.

The vacuum chamber was a 4-inch $(10.2-\mathrm{cm})$ inside diameter Pyrex glass tee. Wall effects that might change operating characteristics were not signigicant because the discharge was confined to the plasma beam and did not fill the chamber. Some of the experiments were duplicated in a 12-inch $(30.5-\mathrm{cm})$ diameter vacuum chamber and the results were the same. The chamber was evacuated with a 4inch $(10.2-\mathrm{cm})$ liquid-nitrogen-trapped diffusion pump. Research grade gases with purity greater than 99.995 volume percent were used.

The operating parameters used by the author in these experiments were:
1. The gas used was argon.

2. The gas flow rate was 25 (atmosphere) cubic centimeters per minute.

3. The cathode-to-anode spacing was 5 centimeters $(\mathrm{cm})$.

4. The tantalum cathode tubes had an inside diameter of 0.125 inches $(0.318 \mathrm{~cm})$ and an outside diameter of 0.250 inches $(0.635 \mathrm{~cm})$.

These parameters will be referred to as the standard operating parameters. The procedure used in the investigation was to vary one of these parameters while, unless otherwise stated, maintaining the others at these standard conditions.

The effect of varying the argon-flow rate is shown in Figure 6. The curves show that, over the range investigated, increasing the gas-flow rate decreases the potential required to maintain the arc. This behavior is typical of most discharges in that increasing the gas pressure reduces the voltage required to maintain the discharge. This phenomenon can be attributed to the increase in number of charge carriers associated with an increase in gas pressure.

In another experiment, five different noble gases were used to determine the effect of gas type on the arc. They were helium, neon, argon, krypton, and xenon. The other operating parameters were the standard parameters previously listed. The results of the experiments are shown in Figure 7. Note the curves are in order of size of the atom, the largest (xenon) requiring the least potential to maintain the discharge. No data for neon and helium are shown in Figure 7 because the high current power supply (welder) lacked sufficient voltage to maintain these arcs under the standard conditions. To produce neon and helium arcs, it was necessary to greatly increase the gas-flow rate which, as previously shown, reduces the potential required to maintain the arc. Since increasing the helium-flow rate much more than the neon-flow rate was necessary, it is concluded that the curves for these two gases would also have been in order of atomic size had it been possible to measure them under the standard conditions. 
RFP-1965

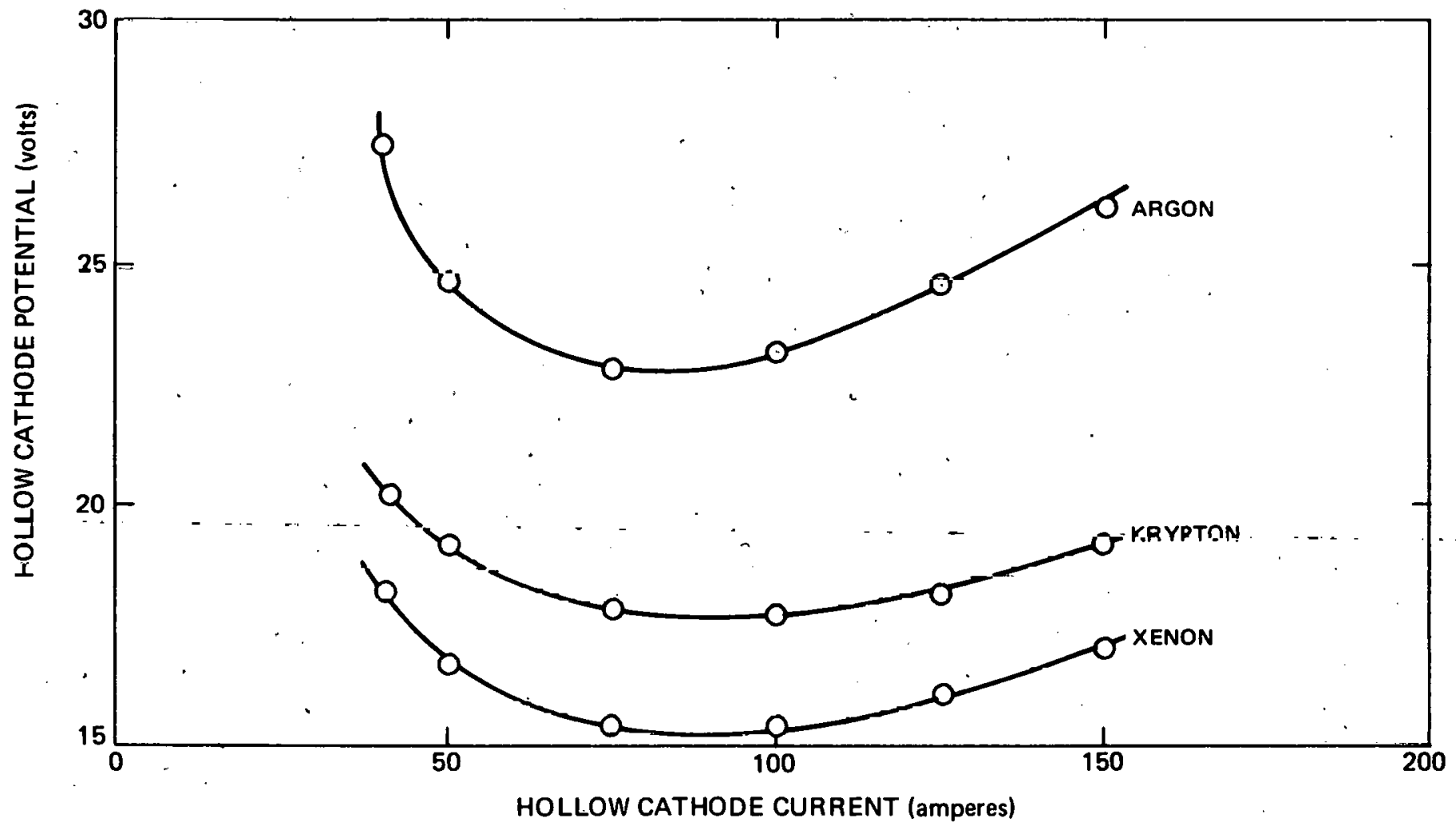

FIGURE 7. The Effect of Gas Type on Hollow Cathode Operation.

FIGURE 8. The Effect of Cathode-Tube Inside Diameter on Hollow Cathode Operation. (Dimensions in inches.)

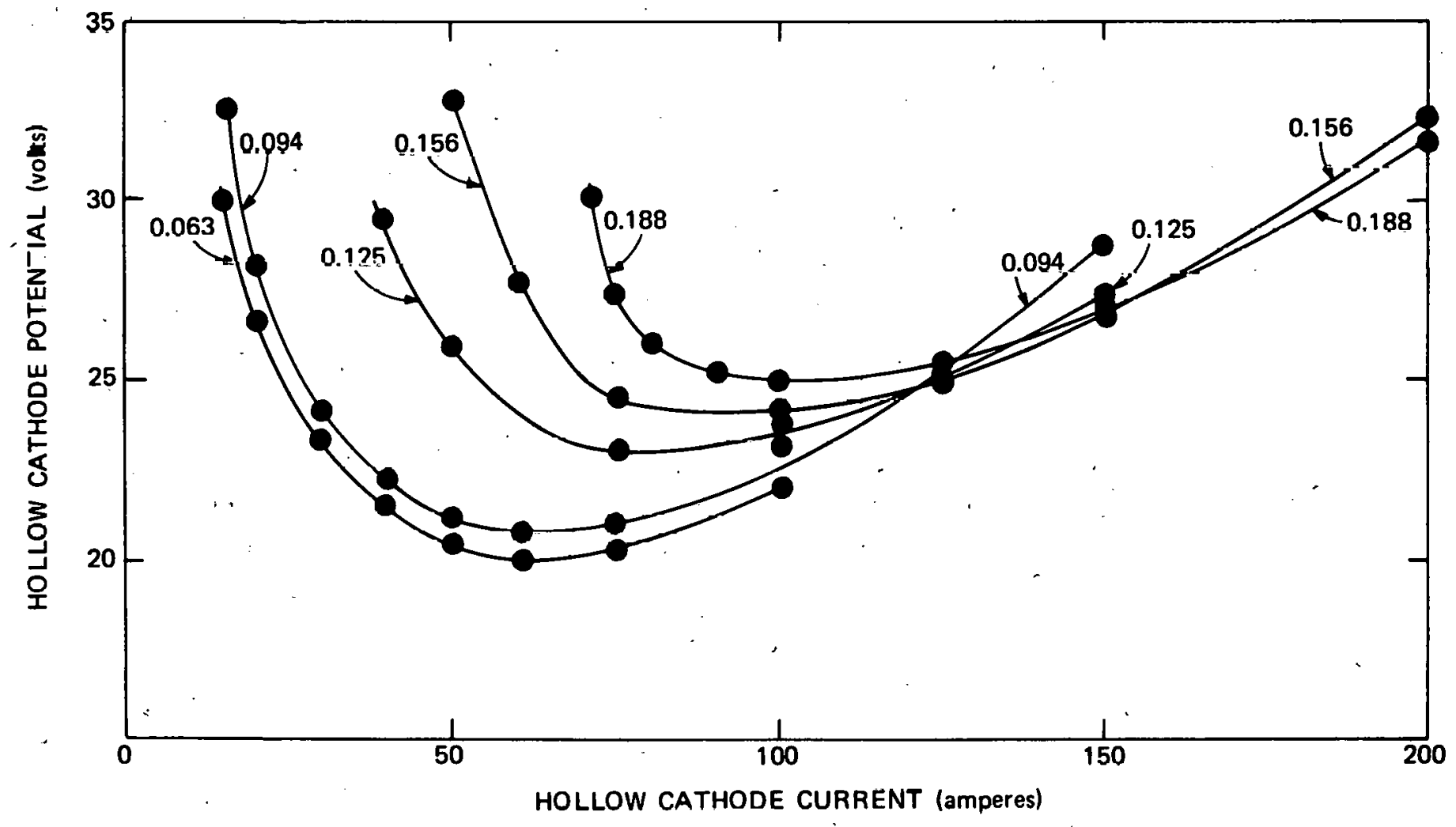


This same order also occurs in glow discharges $(28,29)$ and in other types of DC arcs $(30)$. One factor undoubtedly enhancing higher currents relates to the lower ionization potential of the larger atoms.

The effect of varying the inside diameter of the tantalum cathode tubes is shown in Figure 8. The outside diameter of the tubes was 0.25 inches $(0.635 \mathrm{~cm})$. Other operating parameters were the standard parameters previously listed. Interpretation of these data is difficult because reduction in tube diameter causes an increase in gas pressure within the tube, even though the gas-flow rate is held constant. This probably accounts for the observation that the smaller diameter tubes required less voltage to maintain the arc than did the larger tubes. The shift of the curves to the right (to higher currents) with increasing tube diameter may be attributed to the greater emitting surface of larger diameter tubes.

The highest current data point on each curve (Figure 8 ) is a rough indication of the maximum current at which that size cathode can be operated for extended periods in the horizontal position. At higher current levels, tantalum melted on the inside of the cathode tube runs to the bottom of the tube and obstructs the gas channel or is ejected from the tip (see Figure 9). If the cathode is mounted in a vertical position, the molten

FIGURE 9. Tantalum Cathode-Tube Failure by Melting.

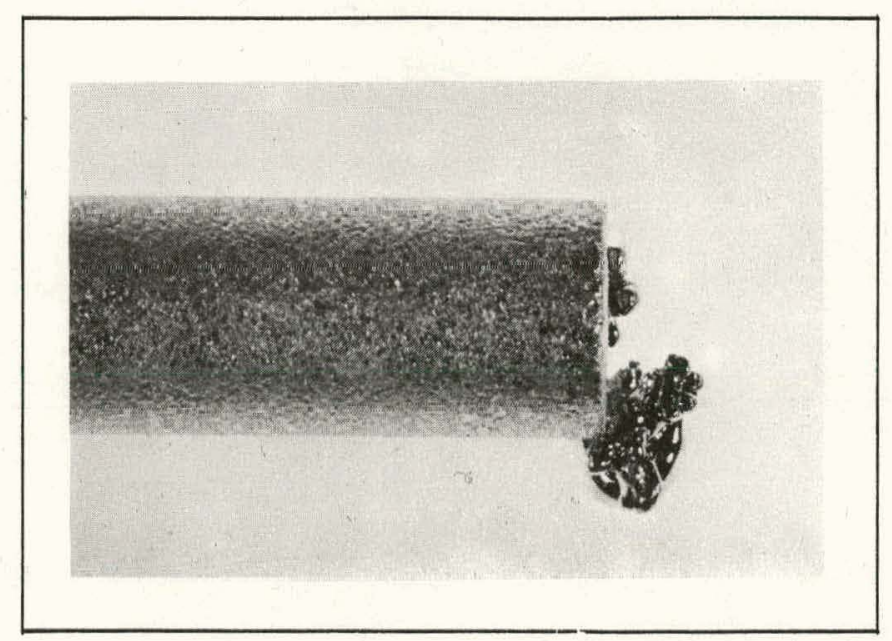

tantalum seems to wet evenly around the tube. Current levels in vertical tubes up to 50 percent greater than in horizontal tubes are possible.

With use, a ring is eroded away around the inside of the cathode tube. In the tube in Figure 10, the eroded ring occurs at a distance from the end of the tube approximately equal to its diameter. This distance depends on the tube diameter and the gas flow rate (26). The eroded zone is the zone of most intense ion bombardment, and is, in fact, caused by such action. It is also the hottest zone, as visually evident during operation. Most of the material removed from the sputtered zone is deposited on either side of it. Since little of the tantalum escapes from the tube, cathode life is much longer than might be expected. Most losses of cathode material occur during startup when intermittent arcing occurs at the tip of the cathode. When the arc becomes stable, losses are small. The cathode tube shown in Figure 10 was subjected to 13 startups and operated for 1 hour and 39 minutes, at an average current level of more than 150 amperes. The weight loss was 0.30 grams. The tube probably could have been used for several more hours.

Erosion of the cathode changes the voltage-current characteristics of the cathode tube to that of a larger diameter tube. To minimize this effect, only new cathodes were used in the experiments and measurements were made as quickly as possible.

FIGURE 10. Erosion of Inside of Tantalum Cathode Tube.

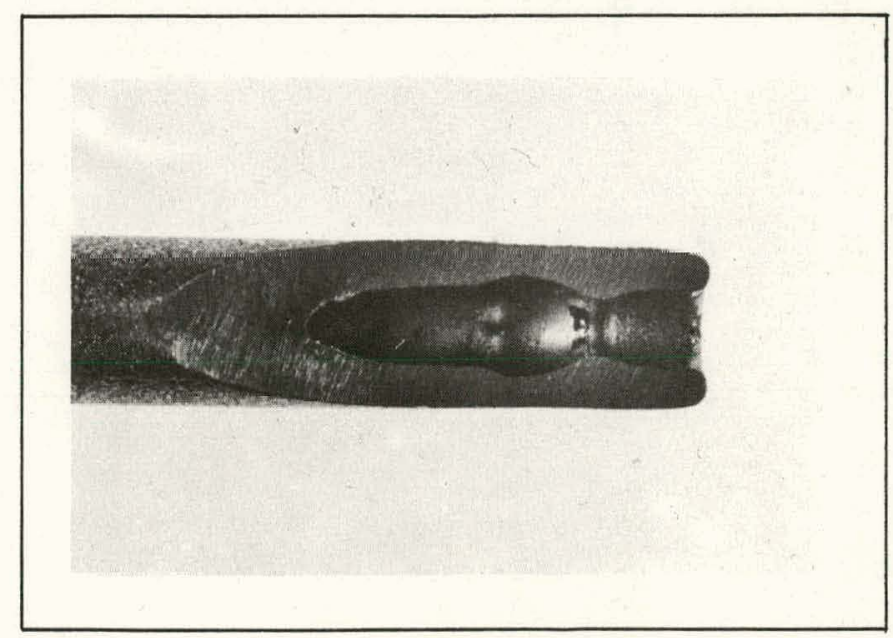


With small inside diameter cathodes, the intensity of the ion bombardment is particularly great and the erosion process rapid. Erosion is probably the reason the potential-current curve for the 0.063 inch $(0.16-\mathrm{cm})$ inside diameter cathode is so similar to that of the 0.094 -inch $(0.24-\mathrm{cm})$ cathode. The operation of extremely small inside diameter cathodes for extended periods is not feasible.

The effect of varying the wall thickness of the cathode tubes is shown in Figure 11. The data show it is necessary with thicker cathode walls to apply a higher potential to produce the same current. This reduction in cathode efficiency can probably be attributed to the greater external surface area available to radiate energy, which in turn causes the cathode to operate at a lower temperature.

Two series of experiments were performed to determine the effect of varying the cathode to anode spacing. In one set of experiments the hollow cathode was operated at standard conditions except for cathode-to-anode spacing. The spacing was varied from 5 to $15 \mathrm{~cm}$, and the cathode potential necessary to produce 50,100 , and 150 amperes of cathode current was measured. The results of the experiment are shown in Figure 12. The data are consistent with the usual observation in gas discharges that the electrode phenomena are largely independent of the cathode-to-anode spacing, and the electric field in the positive column is

FIGURE 11. The Effect of Cathode-Tube Outside Diameter on Hollow Cathode Operation.

\section{Legend}

A. 0.375 -inch outside diameter (OD) $X$

0.188 -inch inside diameter (ID).

B. 0.313 -inch $O D \times 0.188$-inch ID.

C. 0.250 -inch OD $\times 0.188$-inch ID.

D. 0.250 -inch $O D \times 0.063$-inch ID.

E. 0.188-inch OD $\times$ 0.063-inch ID.

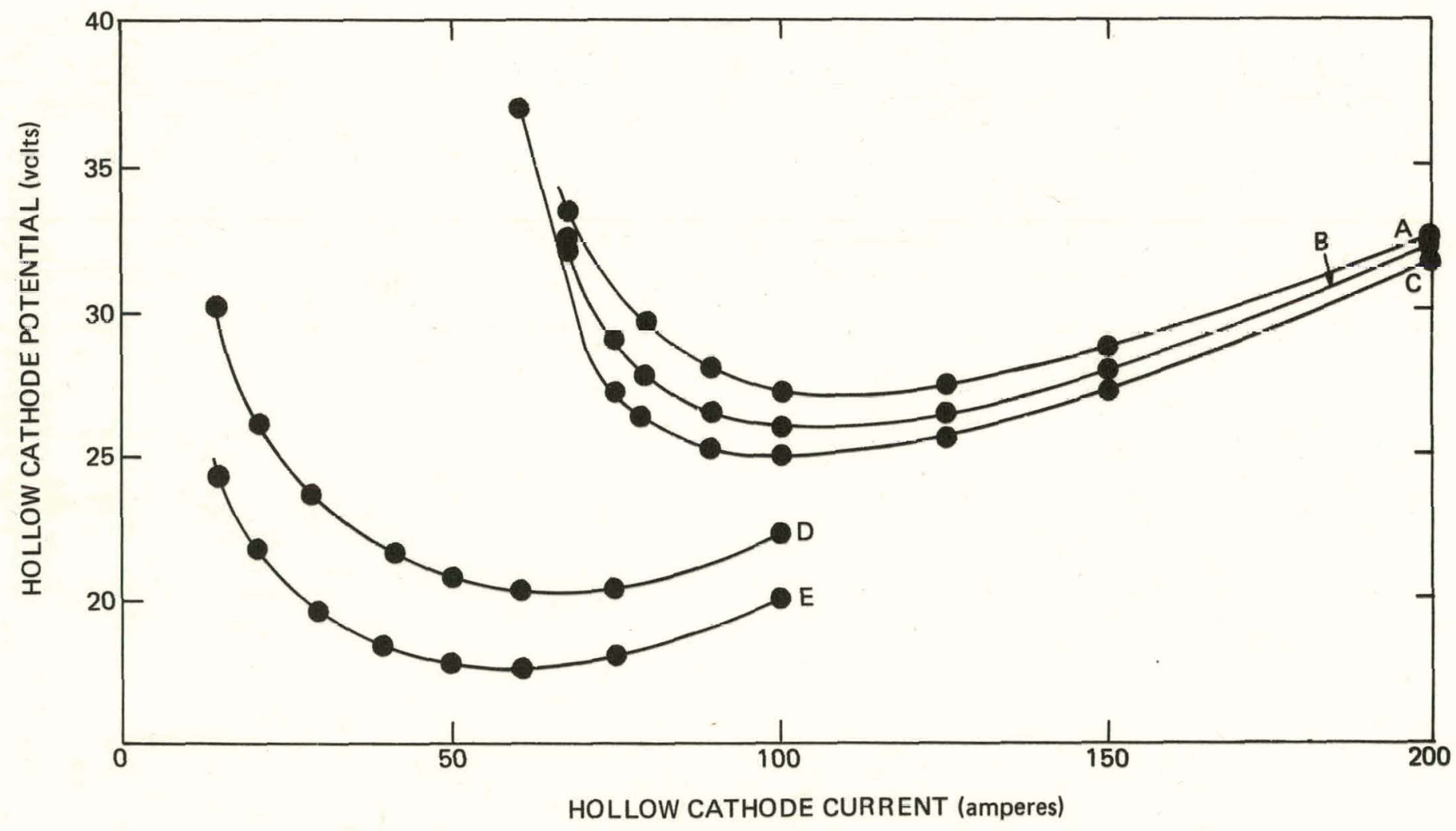


macroscopically uniform. If so, the data also indicate most of potential drop occurs in the electrode regions. The experiments also verify maximum arc conductance occurs near the minimum of the cathode voltage versus cathode-current curve.

The second series of cathode-to-anode spacing experiments was designed to show the effect of argon-flow rate on hollow cathode operation at various cathode-to-anode spacings. These experiments were done with standard operating parameters

- (except spacing) and with a cathode current of - 100 amperes. The results are shown in Figure 13 and are consistent with the other experimental data.

During the course of the cathode-to-anode spacing experiments, the size of the beam at the anode was visually estimated. At $5-\mathrm{cm}$ spacing and under all operating conditions, the beam appeared to be approximately $0.5 \mathrm{~cm}$ in diameter. At greater spacing, spreading of the beam away from the cathode is visually evident. With $10-\mathrm{cm}$ spacing, the diameter of the beam at the anode varied somewhat with argon-flow rate from about $1 \mathrm{~cm}$ at 40 (atmosphere) cubic centimeters per minute to $2 \mathrm{~cm}$ at $25(\mathrm{~atm}) \mathrm{cm}^{3}$ per minute. With a spacing of $15 \mathrm{~cm}$, the boundary of the beam near the anode becomes diffuse and estimation of its diameter is difficult. In all cases observed, however, it was greater than $5 \mathrm{~cm}$.

Measurements were made to determine what fraction of the electrical energy supplied to the cathode was converted to heat at the anode. These values were determined by measuring the increase in anode cooling-water temperature. The experiments were performed using the standard conditions except for argon-flow rate which was increased to 35 (atm) $\mathrm{cm}^{3}$ per minute. The increase permitted measurements at 200 amperes of arc current with the available power supplies. The percentage of electrical energy converted to anode heat (heating efficiency) increased with arc current (Figure 14) reaching 80 percent at 200 amperes. Losses are attributed to radiation from the cathode and the

FIGURE 12. The Effect of Cathode-Anode Spacing (argon-flow rate 25 atmospheric cubic centimeters per minute).

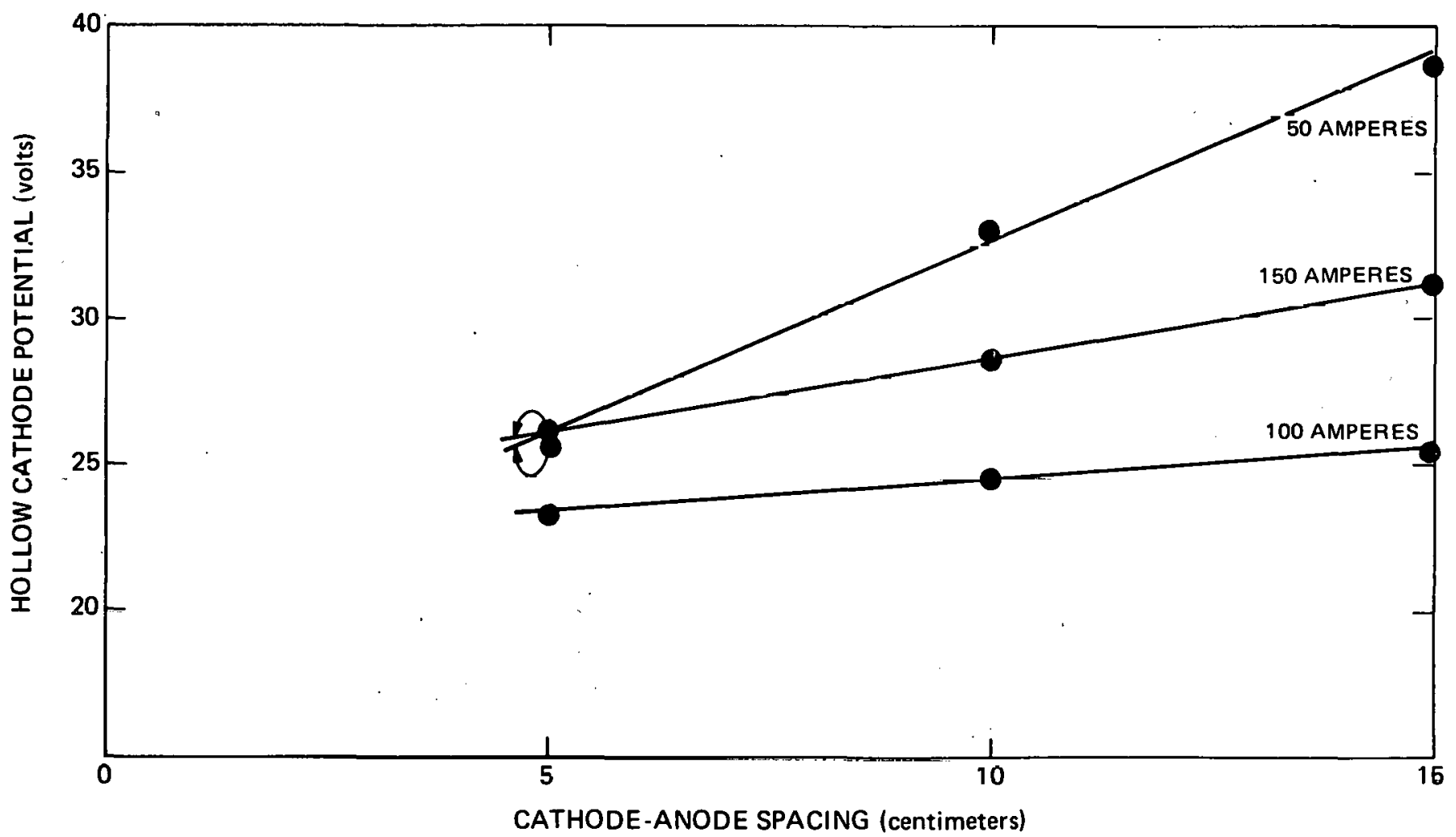




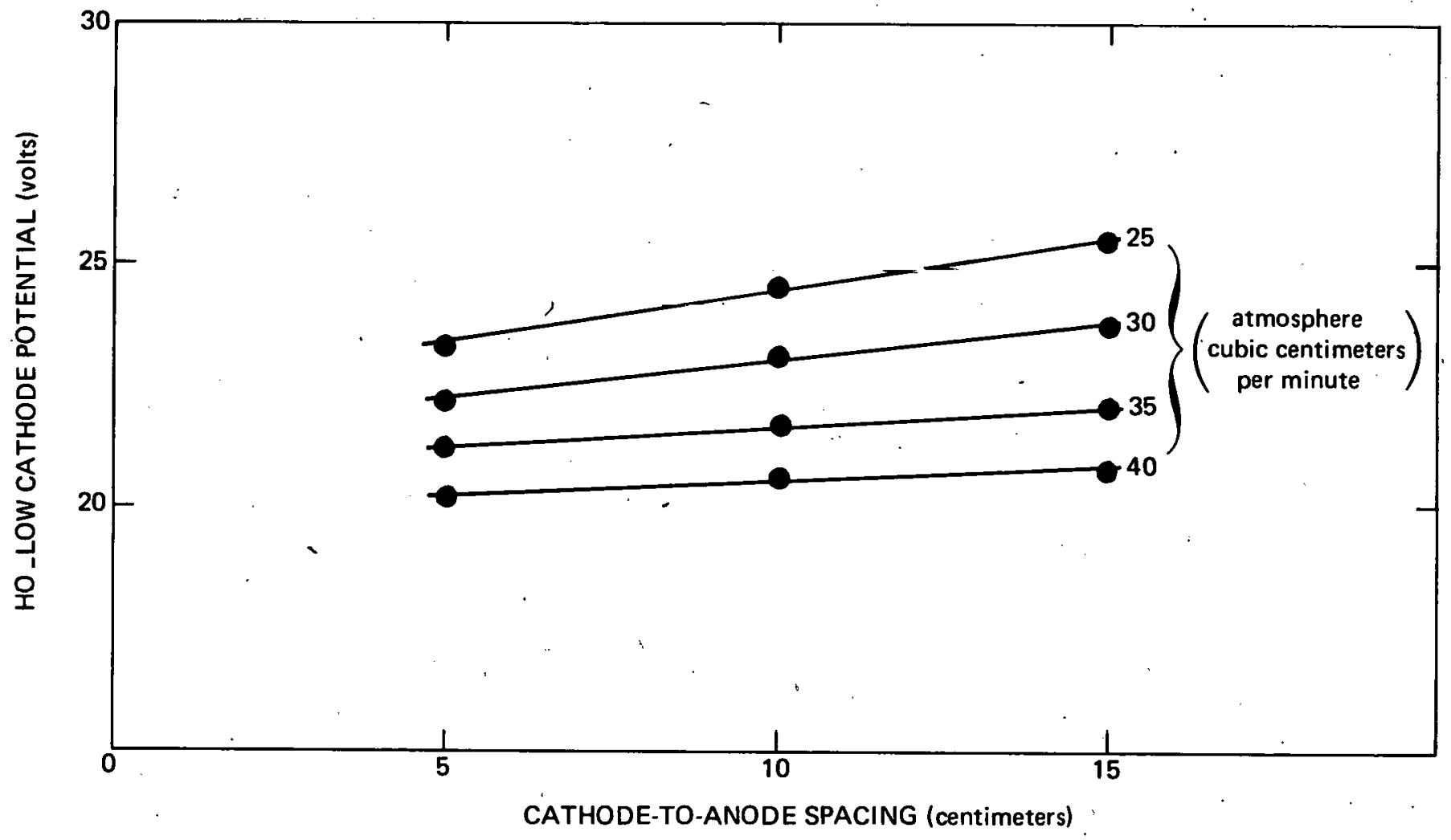

FIGURE 13. The Effect of Cathode-Anode Spacing (cathode current 100 amperes).

FIfIIRF 14 The Heating F.fficiency of Hollow Cathode Arcs.

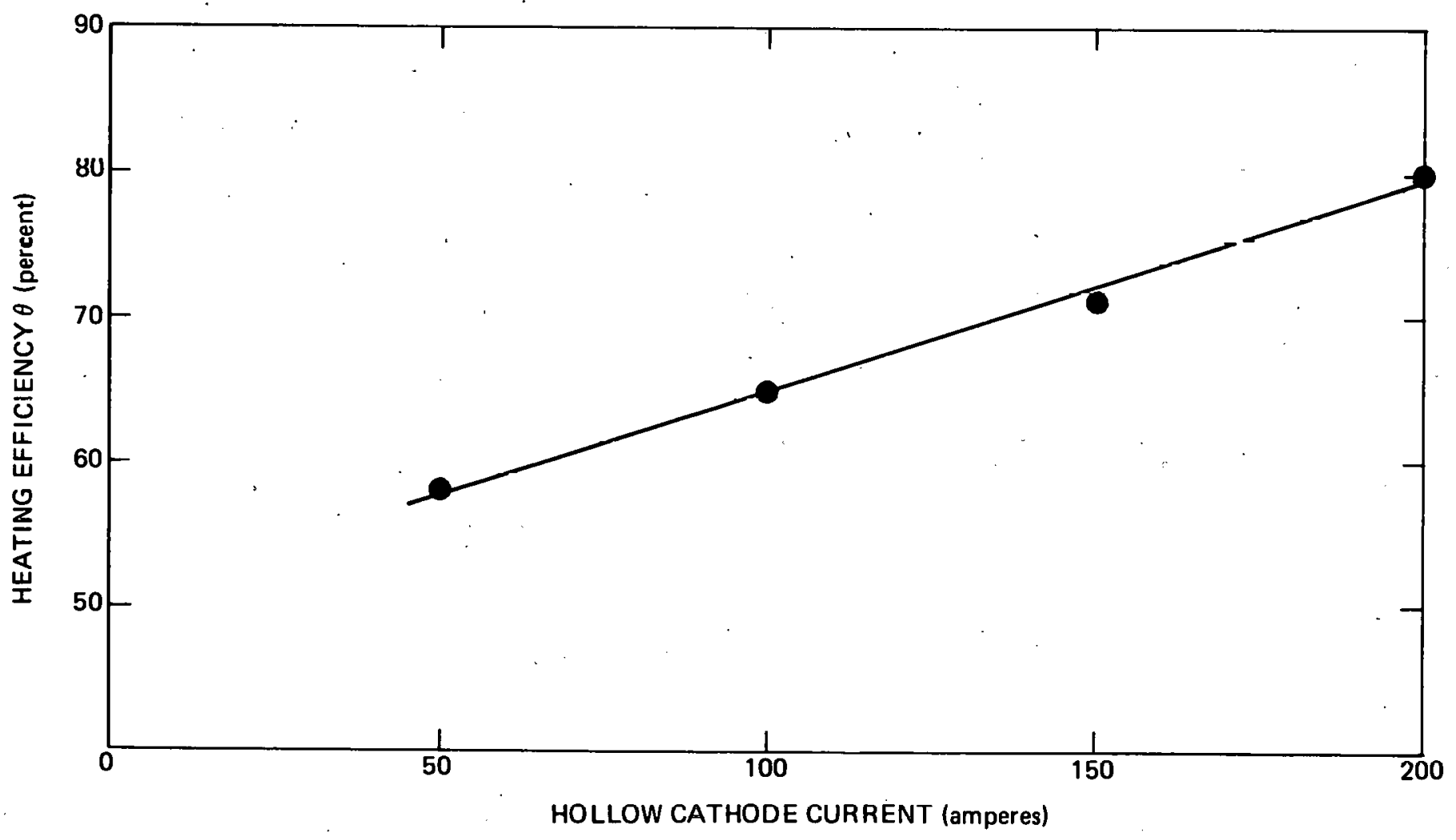


plasma beam, and to conduction through the cathode support.

\section{REFERENCES}

1. J. S. Luce. "Intense Gaseous Discharges." Proceedings of Second United Nations International Conference on the Peaceful Uses of Atomic Energy 31:305. The United Nations, Geneva, Switzerland. 1958.

2. L. M. Lidsky, S. D. Rothleder, D. J. Rose, S. Yoshikawa, C. Michelson, and R. J. Macklin, Jr. "Highly Ionized Hollow Cathode Discharge." Journal of Applied Physics 33:2490. August 1962.

3. L. S. Hall and A. L. Gardner. "Highly Ionized, Steady-State Plasma System." Physics of Fluids 5:7888. July 1962 .

4. A. L. Gardner, W. L. Barr, R. L. Kelly, and N. L. Olcson. "Diagnostic Measurements of a Highly Ionızed Steady-State Plasma." Physics of Fluids 5:794. July 1962.

5. R. Cano, M. Capet, I. Fidone, M. Mattioli, and R. Papoular. "Etude de l'Emission d'un Arc dans le Visible et l'Infrarouge l'oirtain." Page 315. Proceedings of the Six th International Conference of Ionization Phenomena in Gases. Volume 3. P. Humert and E. Crémieu-Alcan, Editors. Ministére d'Etat Charge' de la Recherche. Scientifique et des Questions Atomiques et Spatiales, Paris, France. 1963.

6. A. S. Roberts, Jr. and W. H. Bennett." "Plasma Temperature Measurement for the Hollow Cathode Discharge." Journal of 1 pplicd Physics 35:3434. December 1964.
7. D. L. Morse. "Plasma Rotation in a HollowCathode Discharge.". Physics of Fluids 8:516. March 1965.

8. R. Cano, I. Fidone, and M. Mattioli. "Thermal Bremsstrahlung from Inhomogeneous Plasma." Plasma Physics (Journal of Nuclear Energy Part C) 8:507. 1966.

9. C. B. Kretschmer. Research on Unstable Oscillations in Energetic Arcs. AFOSR 66-0890. Air Force Office of Scientific Research, Washington, District of Columbia. May 1966.

10. I. Alexeff, W. Halchin, W. D. Jones, and J. F. Potts. Plasma-Density Measurement in a Hollow-Cathode Arc by Arc Reversal. ORNL4010. Oak Ridge National Laboratory, Oak Ridge, Tennessee. September 1966.

11. C. B. Kretschmer, F. Boeschoten, and L. J. Demeter. "Plasma Waves and Rotation in the Gas-Fed Hollow Cathode Arc." Physics of Fluids 11:1050. May 1968.

12. M. Hudis, K. Chung, and D. J. Rose. "Ion Temperature, Charge Exchange, and Coulomb Collisions in an Argon Plasma Column." Journal of Applied Physics 39:3297. June 1968.

13. R. Bleekrode and W. van Benthem. "Spectroscopic Investigations of High-Current Hollow Cathode Discharges in Flowing Nitrogen at Low Pressures." Journal of Applied Physics 40:5274. December 1969 .

14. J. R. Morley. "Hollow Cathode Discharge Beams in Vacuum Processing." Page 186. Transactions of the Vacuum Metallurgy Conference 1963. R. F. Bunshah, Editor. The Aniteicuan Vacuum Suciely, Boston, Massachusetts. 1963. 
15. J. R. Morley. "The Hollow Cathode Discharge." Page 368. Proceedings of the Fifth Annual Meeting of the Electron Beam Symposium. J. R. Morley, Editor. Alloyd Electronics Corporation, Cambridge, Massachusetts. 1963.

16. S. Kashu, S. Nishino, and C. Hayashi. "An Assessment of Hollow Cathode Electron Beam Melting." Page 771. International Transactions Vacuum Metallurgy Conference 1967. E. L. Foster, Editor. American Vacuum Society, New York. 1967.

17. S. Kashu, S. Nishino, and C. Hayashi. "High Output Plasma Electron Gun." Page 22. Electron and Ion Beam Science and TechnologyThird International Conference. R. A. Bakish, Editor. The Electrochemical Society, New York. 1968.

18. H. Takei and Y. Yoneda. "Vacuum Heat Treating Using Plasma EB [Electron Beam]." Journal of Vacuum Science and Technology 7:\$36. November-December 1970.

19. D. A. Huchital and J. D. Rigden. "Argon Laser Action in a Thermionic Hollow Cathode Discharge." IEEE Journal of Quantum Electronics QE3:378. September 1967.

20. D. A. Huchital and J. D. Rigden. "Functional Ion Laser Based Upon a Thermionic Hollow Cathode Discharge." Review of Scientific Instruments 39:1472. October 1968.

21. J. H. Noon, E. H. Holt, W. C. Jennings, and R. G. Buser. Argon Ion Laser Utilizing $A$ Hollow Cathode Gas-Fed Arc. ECOM-3032. United States Army Electronics Command, Fort Monmouth, New Jersey. October 1968.

22. W. C. Jennings, J. H. Noon, E. H. Holt, and R. G. Buser. "Comparison of Hollow Cathode and Conventional Argon Ion Lasers." Review of Scientific Instruments 41:322. March 1970.

23. R. J. Carbone and W. J. Witteman. "Tantalum Hollow Cathode in an Argon Ion Laser Tube." Review of Scientific Instruments $41: 322$. March 1970.

24. E. T. Gerry and D. J. Rose. "Combined AnodeCathode Feed of a Hollow-Cathode Arc." Journal of Applied Physics 37:2725. June 1966.

25. E. L. Boyer and J. F. Holt. Experimental Comparison of Conventional-Hollow Cathode Low-Pressure Arcs. AFAPL-TR-67-63. Air Force Aero Propulsion Laboratory, WrightPatterson Air fiorce Base, Ohio. June 1967.

26. J. L. Delcroix, H. Minoo, and A. R. Trindade. "Gas-Fed Multichannel Hollow Cathode Arcs." Review of Scientific Instruments 40:1555. December 1969.

27. M. F. Hoyaux. "Cathodic Phenomena." Chapter 7. Arc Physics. Volume 8. Applied Physics and Engineering Series. SpringerVerlag, New York. 1968.

28. A. von Engel. "Glow Discharge." Chapter 8. Ionized Gases. Oxford University Press, London, England. 1965.

29. B. N. Klyarfel'd, L. G. Guseva, and A. S. Pokrovskaya-Soboleva. "Glow Discharge at Low Pressures and Current Densities up to $0.1 \mathrm{~A} / \mathrm{CM}^{2}$ [0.1 Amperes per Square Centimeters]." Soviet Physics-Technical Physics 11:520. 1966.

30. H. S. Morton and R. M. Gage. "Arc Properties in the Five Rare Gases." Page 8. Arcs in Inert Atmospheres and Vacuum. W. E. Kuhn, Editor. John Wiley and Sons, New York. 1956. 